\title{
Permanência e evasão escolar em cursos técnicos da área da indústria: um estudo sobre escolas de educação profissional de Joinville/SC ${ }^{1}$
}

Persistence and dropout in technical courses on industry area: a study of professional education schools in the city of Joinville/SC

\author{
Alexsandra Joelma Dal Pizzol Coelho ${ }^{2}$ \\ Nilson Marcos Dias Garcia ${ }^{3}$
}

\section{RESUMO}

São apresentados os resultados parciais de uma pesquisa em andamento realizada com estudantes trabalhadores, docentes e equipe técnica pedagógica de escolas de educação profissional públicas de Joinville/SC, objetivando identificar e analisar os elementos motivadores da permanência ou evasão de trabalhadores estudantes nos cursos técnicos na área da indústria, nestas instituições. Apesar de quantificada, a revisão bibliográfica sobre a temática apontou escassez de investigações e de publicações que tratem das motivações da evasão de alunos, em especial na educação profissional. Menos ainda se encontraram trabalhos acadêmicos que estudassem as iniciativas visando a permanência dos alunos em suas instituições. Conclui-se que os altos índices de evasão e escassez de pesquisas demonstram a necessidade de investimento e esforços para estudar a evasão na educação profissional, principalmente para iniciar a reflexão no ambiente escolar e a produção de material que dê suporte teórico e metodológico para futuras pesquisas e trabalhos nesta área.

Palavras-chave: Educação Profissional, Permanência, Evasão, Educação e trabalho.

\begin{abstract}
Presents the partial results of an ongoing research with student workers, teachers and pedagogical staff of public professional education schools in the city of Joinville / SC, aiming to identify and analyze the factors motivating the persistence or dropout of student workers attending technical courses on industry area in these institutions. Although quantified, a literature review on the topic pointed shortage of investigations and publications that address the motivations of dropout students, particularly in professional education. Even less academic papers were found that studied the initiatives aiming the persistence of students in their institutions. Conclude that the high dropout rates and lack of research works demonstrate the need for investment and efforts to study dropout in professional education, mainly to start thinking in the school environment and the production of material that supports the theoretical and methodological framework for future research and work in this area.
\end{abstract}

Keywords: Professional Education, Persistence, Dropout, Education and Work

\footnotetext{
1 Trabalho apresentado no dia 17 de outubro de 2013, no Grupo de Trabalho 23 - Educação Profissional Técnica e Tecnológica - Políticas e Programas de Desenvolvimento Institucional e Pedagógico.

${ }^{2}$ Especialista em PROEJA pelo Instituto Federal de Educação, Ciência e Tecnologia (IFSC), mestranda no Programa de Pós-Graduação em Tecnologia (PPGTE) da Universidade Tecnológica Federal do Paraná (UTFPR); Pedagoga no Instituto Federal de Educação, Ciência e Tecnologia de Santa Catarina (IFSC), campus Joinville. E-mail: alexsandra@ifsc.edu.br

${ }^{3}$ Doutor em educação pela universidade de São Paulo (USP), professor do Departamento Acadêmico de Física e do Programa de Pós-graduação em Tecnologia (PPGTE) da Universidade Tecnológica Federal do Paraná (UTFPR). E-mail: nilson@utfpr.edu.br
} 


\section{INTRODUÇÃO}

A cidade de Joinville, em Santa Catarina, é o terceiro maior pólo industrial da região sul, uma cidade que vive em seu cotidiano a cultura do trabalho. Dentro desta realidade local, escolas públicas e privadas ofertam cursos técnicos na área da indústria, procurados principalmente por trabalhadores desta área.

$\mathrm{Na}$ cidade, de acordo com dados de maio de 2013 do SISTEC (Sistema Nacional de Informações da Educação Profissional e Tecnológica), existem dezoito escolas de educação profissional, sendo duas públicas e as demais privadas. Destas, seis escolas ofertam os cursos na área da indústria, totalizando quarenta e duas ofertas de cursos técnicos nesta área, que absorvem cerca de 1460 matrículas de alunos em cursos técnicos só na educação profissional pública da cidade (BRASIL, 2012).

Boa parte de seus alunos pretendem ser absorvidos pelas indústrias da região depois de formados ou já são trabalhadores que retornam aos estudos formais para se qualificarem e, usualmente, buscarem melhores condições de trabalho e de salário em seus empregos.

Uma das preocupações do corpo diretivo dessas instituições diz respeito à necessária permanência de seus alunos para que possam concluir seus cursos, acompanhando, sempre que possível, as motivações que levam ao abandono dos bancos escolares por parte dos estudantes, números que, usualmente, são preocupantes.

Pesquisa realizada em 2011 no Instituto Federal de Educação, Ciência e Tecnologia de Santa Catarina, campus Joinville, por exemplo, mostra que, em 2011, "64\% dos alunos desistem dos cursos técnicos em Eletroeletrônica e Mecânica Industrial devido ao trabalho" (COELHO et al, 2011), indicando um alto índice de evasão escolar dos estudantes trabalhadores.

Apesar dessas constatações, tem-se observado que são poucas as investigações que procuram analisar os diversos elementos que motivam os estudantes trabalhadores a permanecerem ou desistirem dos cursos técnicos que estão frequentando, o que torna relevante esta pesquisa, que, por ter razões multifatoriais, envolveu os diversos segmentos da escola, ou seja, o estudante trabalhador, o docente e a equipe técnica pedagógica, além de ser considerado o 
contexto político e social em que se inserem as escolas e mesmo os estudantes trabalhadores.

\section{AS PESQUISAS SOBRE EVASÃO E PERMANÊNCIA}

A taxa média de distorção idade-série no Ensino Médio no Brasil é de 34,4\% e Santa Catarina é o Estado brasileiro com menor taxa de distorção idade-série no Ensino Médio, apresentando um percentual de 16,7\% (BRASIL, 2011a). Porém, apesar de ter uma ampliação nos últimos anos nos índices de permanência e sucesso na educação básica, "os índices, ainda são extremamente ruins, particularmente para as pessoas pobres, onde cerca de $80 \%$ dos jovens entre 18 e 24 anos ainda não concluiu o ensino médio" (BRASIL, 2011a, p.36).

Ainda com relação ao Ensino Médio, os dados de Rendimento Escolar no país, apontam que, em 2011, 13,1\% dos estudantes do Ensino Médio não obtiveram êxito escolar e 9,5\% dos estudantes da última etapa da educação básica desistiram do curso (BRASIL, 2011b).

Entretanto, quando se buscam dados relativos à Educação Profissional, esta tarefa se torna mais difícil, pois embora o Ministério da Educação (MEC) realize o Censo Escolar de toda educação básica e profissional anualmente, os dados relativos ao rendimento escolar (aprovação, reprovação e abandono) dos estudantes do ensino técnico não constituem um campo de preenchimento obrigatório no censo e apenas informações sobre matrícula e conclusões são disponibilizadas pelo INEP (Instituto Nacional de Estudos e Pesquisas Educacionais Anísio Teixeira) referentes à Educação Profissional e "os dados de conclusão, por sua vez, são tão díspares em relação aos de matrícula que, embora possam sugerir forte evasão, é uma temeridade aventar qualquer hipótese quantitativa sobre esse problema" (DORE; LÜSCHER, 2011, p.783).

Segundo Dore e Lüscher (2011), a falta de informação sobre evasão escolar no ensino técnico no Brasil abrange tanto o referencial teórico quanto o empírico, dificultando a construção de indicadores adequados para investigações sobre esse problema.

De acordo com essas autoras, 
Quando se trata da educação técnica não há pesquisas e/ou informações sistematizadas sobre a evasão, conforme verificado em pesquisa realizada na base de dados da Faculdade de Educação da Universidade Federal de Minas Gerais, que dispõe de $100 \%$ das revistas científicas publicadas no Brasil na área educacional. (DORE; LÜSCHER, 2011, p. 782)

Essa afirmação pode ser evidenciada pelo levantamento de teses e dissertações que tratassem da temática Evasão/Permanência de alunos de cursos técnicos ou tecnológicos. Dos dezessete trabalhos identificados, dois são referentes a cursos superiores de tecnologia, quatro sobre cursos técnicos e quatro sobre evasão ou permanência no PROEJA - Programa Nacional de Integração da Educação Profissional com a Educação Básica na Modalidade de Jovens e Adultos. Assim, apenas duas das dezessete produções faziam relação a motivadores da permanência e da evasão.

Da mesma forma, ao se pesquisar artigos publicados sobre essa temática foram obtidos os resultados apresentados na tabela 1:

Tabela 1 - Artigos publicados referentes à evasão e permanência

\begin{tabular}{|c|c|c|c|}
\hline Local pesquisado & $\begin{array}{c}\text { Tema } \\
\text { pesquisado }\end{array}$ & $\begin{array}{l}\text { Quantidade de } \\
\text { publicação }\end{array}$ & Publicações significativas \\
\hline \multirow{6}{*}{$\begin{array}{l}\text { Site } \\
\text { www.scielo.org }\end{array}$} & $\begin{array}{l}\text { Evasão } \\
\text { escolar }\end{array}$ & 41 artigos & $\begin{array}{l}02 \text { - Evasão no Ensino } \\
\text { Superior; } \\
01 \text { - Evasão EPT; } \\
02 \text { - Evasão EJA; } \\
03 \text { - Evasão de crianças e } \\
\text { adolescentes trabalhadores; } \\
09 \text { - Evasão na educação } \\
\text { básica; } \\
03 \text { - Evasão e fracasso } \\
\text { escolar; }\end{array}$ \\
\hline & $\begin{array}{l}\text { Abandono } \\
\text { da escola }\end{array}$ & 53 artigos & $\begin{array}{l}01 \text { - EPT nível Médio; } \\
\text { As demais publicações fazem } \\
\text { referencia ao abandono em } \\
\text { relação à gravidez precoce, } \\
\text { drogas, violência de jovens e } \\
\text { crianças; }\end{array}$ \\
\hline & $\begin{array}{l}\text { Permanênci } \\
\text { a e êxito }\end{array}$ & 15 artigos & $\begin{array}{l}01 \text { - Alunos em } \\
\text { vulnerabilidade e risco social; }\end{array}$ \\
\hline & $\begin{array}{l}\text { Permanênci } \\
\text { a EPT }\end{array}$ & 05 artigos & 02 - EPT nível médio \\
\hline & $\begin{array}{l}\text { Trabalhador } \\
\text { estudante }\end{array}$ & 02 artigos & $\begin{array}{l}\text { Aborda sobre trabalho e } \\
\text { estudo sobre enfermagem; }\end{array}$ \\
\hline & $\begin{array}{l}\text { Educação } \\
\text { Profissional }\end{array}$ & 01 artigo & 01 - EPT nível médio \\
\hline
\end{tabular}




\begin{tabular}{|c|c|c|c|}
\hline \multirow[t]{4}{*}{ Local pesquisado } & $\begin{array}{c}\text { Tema } \\
\text { pesquisado }\end{array}$ & $\begin{array}{l}\text { Quantidade de } \\
\text { publicacão }\end{array}$ & Publicações significativas \\
\hline & e Evasão & & \\
\hline & $\begin{array}{l}\text { Educação } \\
\text { Profissional }\end{array}$ & 776 artigos & $\begin{array}{l}02 \text { - Relacionados evasão na } \\
\text { EPT }\end{array}$ \\
\hline & $\begin{array}{l}\text { Trabalhar e } \\
\text { estudar }\end{array}$ & 24 artigos & $\begin{array}{l}01 \text { - EJA; } \\
02 \text { - Ensino Superior; } \\
02 \text { - Trabalho de crianças e } \\
\text { adolescentes; } \\
\text { zero - EPT; }\end{array}$ \\
\hline $\begin{array}{l}\text { Publicações da } \\
\text { ANPED }\end{array}$ & $\begin{array}{l}\text { Evasão e/ou } \\
\text { permanência }\end{array}$ & 02 & $\begin{array}{l}01-\text { EJA; } \\
01-\text { Exclusão escolar na } \\
\text { EPT. }\end{array}$ \\
\hline $\begin{array}{l}\text { Revista Tecnologia } \\
\text { e Sociedade/ } \\
\text { UTFPR }\end{array}$ & $\begin{array}{l}\text { Evasão e/ou } \\
\text { permanência }\end{array}$ & Zero & Zero \\
\hline $\begin{array}{l}\text { Revista Brasileira } \\
\text { da Educação } \\
\text { Profissional e } \\
\text { Tecnológica/SETE } \\
\text { C/MEC }\end{array}$ & $\begin{array}{l}\text { Evasão e/ou } \\
\text { permanência }\end{array}$ & Zero & Zero \\
\hline $\begin{array}{l}\text { Publicações e } \\
\text { artigos da } \\
\text { SETEC/MEC }\end{array}$ & $\begin{array}{l}\text { Evasão e/ou } \\
\text { permanência }\end{array}$ & Zero & Zero \\
\hline
\end{tabular}

Fonte: Os autores (2013).

Os dados obtidos confirmaram a escassez de produções sobre a evasão e permanência na educação, em especial na educação profissional, foco da pesquisa.

\section{AS POLÍTICAS PÚBLICAS DE APOIO À PERMANÊNCIA ESCOLAR}

Conforme Dore e Lüscher (2011), a evasão e o abandono escolar são contrários às garantias da Constituição Federal de 1988.

\footnotetext{
$\mathrm{O}$ abandono escolar confronta-se com o preceito constitucional segundo o qual é direito da pessoa, além da oportunidade de acesso à escola, ter garantidas as condições de permanência, tendo em vista seu pleno desenvolvimento, seu preparo para o exercício da cidadania e sua qualificação para o trabalho. (DORE; LÜSCHER, 2011, p.779-780).
}

A Lei de Diretrizes e Bases da Educação Nacional - LDB, Lei 9394/96, em seu art. $3^{\circ}$. garante os mesmos princípios de acesso e permanência dos alunos na escola, aspecto que é reforçado no art. $4^{\circ}$., inciso VII, quando estabelece a "oferta de educação escolar regular para jovens e adultos, com características e 
modalidades adequadas às suas necessidades e disponibilidades, garantindo-se aos que forem trabalhadores as condições de acesso e permanência na escola" (BRASIL, 1996).

Entretanto, para Kuenzer (2007), além de não garantir as condições de permanência escolar, o Estado repassa para a sociedade civil a responsabilidade de suas funções.

\begin{abstract}
A partir da alegação da "impossibilidade" do Estado em cumprir com suas funções, pretensamente melhor desempenhadas por organizações privadas mais ágeis, que asseguram mais eficácia e maior ampliação da capacidade de atendimento, as relações entre Estado e sociedade civil passam a se dar por meio das parcerias entre o setor público e o setor privado. (KUENZER, 2007, p. 1174)
\end{abstract}

Com relação à permanência do trabalhador estudante na escola, a LDB, ao se referir à modalidade da Educação de Jovens e Adultos - EJA, estabelece que será viabilizado e estimulado pelo poder público o acesso e permanência deste educando através de ações integradas e complementares (BRASIL, 1996), explicitação essa que não ocorre quando trata do acesso, permanência e garantias do trabalhador estudante no capítulo III da lei supracitada, relativo à educação profissional e tecnológica.

Entretanto, para se fazer cumprir, é necessário que existam mecanismos para tal. Nesse sentido, atualmente, as políticas de apoio à permanência escolar são as de progressão automática e de assistência financeira, conforme ponderam Dore e Luscher (2011, p.780),

Hoje, políticas governamentais de cunho educacional e/ou social, tais como a progressão automática entre as séries, que promove a redução da distorção entre idade e série, e o programa Bolsa Família, contribuem tanto para universalizar o acesso ao ensino fundamental como para conter a evasão estudantil.

Essa política financeira não se resume apenas a Educação Básica. $\mathrm{Na}$ Educação Profissional, em especial na rede federal, há a política de apoio ao estudante regulamentada pelo Decreto 7.234, de 19 de julho de 2010, o qual dispõe sobre o Plano Nacional de Assistência Estudantil. Este Plano consiste de ações de assistência estudantil que são executadas por instituições federais de ensino superior, inclusive os Institutos Federais de Educação, Ciência e Tecnologia, devido às suas especificidades.

De acordo com esse decreto, são objetivos gerais do Plano Nacional de 
Assistência Estudantil:

I - democratizar as condições de permanência dos jovens na educação superior pública federal;

II - minimizar os efeitos das desigualdades sociais e regionais na permanência e conclusão da educação superior;

III - reduzir as taxas de retenção e evasão; e

IV - contribuir para a promoção da inclusão social pela educação. (BRASIL, 2010).

Tendo em vista a existência de tal legislação, é interessante verificar se esse apoio financeiro tem obtido êxito enquanto política e estimulado a permanência dos estudantes.

\section{A TRAJETÓRIA DA PESQUISA}

A pesquisa foi elaborada buscando identificar e analisar, sob a ótica dos diversos atores envolvidos no processo educativo, as motivações e razões que justificam ou explicam a permanência e a evasão dos trabalhadores estudantes nos cursos de formação profissional das instituições investigadas.

Ela está sendo realizada em duas escolas públicas de educação profissional de Joinville/SC, uma federal e outra estadual, e foi motivada pela busca da compreensão deste movimento dos estudantes trabalhadores nos cursos técnicos.

Concebida como uma pesquisa qualitativa, ela envolverá estudantes que permanecem frequentando as escolas e estudantes desistentes, professores e equipe técnica pedagógica. Estão sendo aplicados questionários e programadas entrevistas com os participantes.

Num primeiro momento foi aplicado o instrumento de investigação aos estudantes que frequentam regularmente o curso técnico concomitante em eletroeletrônica da escola da rede federal. Os estudantes estão no III módulo/semestre do respectivo curso e estudam no período noturno. Dos catorze estudantes que participaram da pesquisa, onze possuem vínculo empregatício e oito já pensaram em desistir do curso.

Foi possível constatar que, dos catorze alunos que responderam os questionários, nove são da grade regular e cinco da grade que está em extinção. Como ingressam semestralmente trinta e seis estudantes neste curso e apenas 
nove estão regularmente cursando, conclui-se que o índice de evasão dos estudantes da turma que ingressou no primeiro semestre de 2012 no curso técnico concomitante em eletroeletrônica foi de 75\%. Esses índices motivaram ainda mais compreender porque esses alunos estão evadindo e como a instituição justifica e interpreta esse dado.

Ao questionarmos os estudantes sobre fatores que influenciaram sua decisão em continuar o curso técnico, percebeu-se que a questão que mais influência sua permanência é a qualidade do trabalho docente (93\%), outro ponto significativo para permanência estudantil é a estrutura e prestigio da instituição (64\%), os estudantes consideram primordial a qualidade dos laboratórios, estrutura em geral da escola e principalmente o prestigio e reconhecimento da instituição.

Embora seja um curso de educação profissional e onze destes estudantes trabalharem, as questões do mundo do trabalho não foram elencadas como significativas para sua permanência escolar, pois 78\% dos estudantes consideraram que a pressão profissional não tem importância em sua decisão para continuar o curso e $50 \%$ deles possuem boa perspectiva de conseguir um emprego melhor depois de formado.

À solicitação feita aos permanentes para que indicassem as possíveis suposições para que seus colegas tenham desistido do curso, a maioria sinalizou que são as dificuldades de aprendizagem dos alunos (64\%), bem como as dificuldades que os estudantes possuem para conciliar trabalho e estudo e a falta de tempo para estudar (57\%), o que demonstra uma contradição, pois embora haja uma qualidade docente significativa para permanência dos estudantes e as questões de trabalho não sejam influentes para a evasão, na opinião dos alunos que permaneceram, os alunos estão desistindo dos cursos por não estarem aprendendo e/ou não conseguirem conciliar o estudo com a escola.

Referente à política de apoio estudantil, apenas 7\% dos estudantes permanentes consideram decisivo os auxílios financeiros da Instituição ou do Governo para permanência escolar, sendo que 50\% dos mesmos sinalizaram que, para eles, esse apoio não tem nenhuma importância sobre sua decisão em permanecer no curso técnico. 
Três (21\%) estudantes responderam que conhecem colegas que desistiram por motivos financeiros, o que demonstra que a ausência de acompanhamento dos evadidos dificulta uma maior eficiência da política de assistência estudantil.

Dos quatorze alunos que participaram da pesquisa, cinco (36\%) recebem o beneficio financeiro da assistência estudantil. Entretanto, $78 \%$ dos alunos relataram desconhecer projetos, programas ou ações da instituição voltada para permanência e sucesso dos estudantes e os $22 \%$ que os conhecem não citaram a assistência estudantil, mas sim programas de pesquisa e extensão da instituição. Chama a atenção que nem mesmos os beneficiários do programa os citaram.

Relativo à preocupação e ações da instituição (professores, núcleo pedagógico e direção) com relação à desistência dos alunos, os estudantes permanentes consideram-nas, em geral, pouco adequadas (60\%) e relataram alguns pontos positivos e negativos sobre esses acompanhamentos como:

A coordenação não busca saber da desistência dos alunos. (Permanente 04)

A coordenação dá graças a Deus por o aluno ir embora. (Permanente 11)

Não é oferecida um leque maior de cursos caso a aptidão da pessoa não seja aquilo que está cursando. (Permanente 02)

Sei de casos que a instituição liga para o aluno para voltar. (Permanente 01)

O professor se preocupa com o aluno estar faltando. (Permanente 05)

Esses dados, ainda iniciais, já demonstram a importância do acompanhamento sobre a evasão escolar nos cursos técnicos e indicam algumas motivações para as mesmas. Ao longo do processo, espera-se que, com o restante da pesquisa, seja possível não só melhor compreender as motivações de permanência e abandono destes estudantes, como também, a partir de reflexões e sugestão de ações, contribuir para com a educação do trabalhador e com a práxis das escolas de educação profissional.

\section{CONCLUSÕES E RESULTADOS ESPERADOS}

A escassez de pesquisas sobre permanência e evasão na educação, em especial na formação profissional, demonstram a necessidade de investimentos e esforços para estudar esta temática, principalmente para iniciar, no ambiente escolar, a reflexão e a produção de material que dê suporte teórico e metodológico 
para futuras pesquisas e trabalhos.

Os índices de evasão demonstram a urgência em entender essa questão, pois os dados iniciais, obtidos apenas com os alunos que ainda permanecem estudando, já sinalizam alguns motivadores dessa evasão. Demonstram também, principalmente, os motivos pelos quais os alunos permanecem nos cursos e o que os estudantes trabalhadores procuram e encontram nestes cursos, fornecendo bons indicadores para onde o investimento deve ser canalizado para que os índices de permanência possam superar os de evasão.

Fato que deve ser ressaltado dos resultados obtidos é que as atuais políticas de apoio à permanência escolar, na opinião dos participantes, são pouco eficientes e desconhecidas, indicando que, neste momento em que a educação profissional está em expansão em todo o país, é de fundamental importância repensar ações e programas que intensifiquem o apoio a permanência no ensino técnico.

Ao se questionar os motivadores de permanência e evasão escolar, esperase, a partir das informações obtidas na investigação, oportunizar elementos para elaborar ações junto aos estudantes trabalhadores, professores e equipe pedagógica que, muito mais que quantificar e identificar os motivadores da evasão dos estudantes, possam estimular a permanência dos mesmos na educação profissional.

\section{REFERÊNCIAS}

BRASIL. Lei de Diretrizes e Bases da Educação Nacional: nº 9394/96. Senado Federal, Brasília/DF: 1996.

BRASIL. Decreto no 5.209 de 17 de setembro de 2004. Regulamenta a Lei no 10.836, de 09 de janeiro de 2004, que cria o Programa Bolsa Família, e dá outras providências.

BRASIL. Decreto n 7.234 de 19 de julho de 2010. Dispõe sobre o Programa Nacional de Assistência Estudantil - PNAES.

BRASIL. As desigualdades na escolarização no Brasil: Relatório de observação $n^{\circ}$ 4. Brasília: Presidência da República, Conselho de Desenvolvimento Econômico e Social - CDES, $2^{\mathrm{a}}$ Edição, 2011a. 
BRASIL. MEC. INEP. Sinopse Estatística da Educação Básica. 2011b. Disponível em <http://portal.inep.gov.br/basica-censo-escolar-sinopse-sinopse>. Acesso em 28 de junho de 2013.

BRASIL. MEC. INEP. Dados finais do Censo Escolar 2012, publicados no Diário Oficial da União no dia 21 de dezembro de 2012. Disponível em <http://www.dataescolabrasil.inep.gov.br/dataEscolaBrasil/>Acesso em 20 de maio de 2013.

COELHO, Alexsandra Joelma Dal Pizzol; SANTOS, Maria Conceição Epitácio dos; VALENTE, Eliane Joyce Joo da Silva; ZANIN, Rafael Antônio. Desafios e possibilidades no percurso formativo nos cursos técnicos em Eletroeletrônica e Mecânica Industrial no IF-SC Campus Joinville sob o olhar dos egressos. Artigo de conclusão de projeto de pesquisa. IF-SC, Campus Joinville: 2011

DORE, Rosemary; LÜSCHER, Ana Zuleima. Permanência e Evasão na Educação Técnica de Nível Médio em Minas Gerais. Cadernos de Pesquisa. V.41 N.144 SET./DEZ. 2011.

KUENZER, Acacia Zeneida. Da dualidade assumida à dualidade negada: 0 discurso da flexibilização justifica a inclusão excludente. Educ. Soc., Campinas, vol. 28, n. 100 - Especial, p. 1153-1178, out. 2007. Disponível em $<$ http://www.cedes.unicamp.br>.

OLIVEIRA, Tamara Fresia Mantovani de. Fracasso Escolar: "Cultura do ideal" e "Cultura do Amoldamento". ANPED: 2003. Disponível em <http://www.anped.org.br/reunioes/26/trabalhos/tamarafresiamantovanideoliveira.rtf> . Acesso em 30 de junho de 2013. 